\title{
Avaliação preliminar do emprego de arenito zeolítico da região nordeste do Brasil como material pozolânico para cimento Portland
}

\author{
(Preliminary evaluation of sandstones from northeastern Brazil with \\ pozzolanic properties for Portland cement)
}

\author{
M.S.Picanço, R.S.Angélica, M.S. Barata \\ Instituto de Geociências, Universidade Federal do Pará, Belém, PA \\ marcelopicanco2004@yahoo.com.br
}

\begin{abstract}
Resumo
As zeolitas possuem atividade pozolânica normalmente sem a necessidade de ativação térmica, por isto têm sido empregadas na produção de cimento e concreto hidráulicos desde a época do império romano. Hoje em dia são utilizadas na fabricação do cimento Portland através da substituição do clinquer em percentuais que variam entre 5 e 20\%, dependendo da reatividade e da finura da zeólita. Em razão disto, são muito importantes do ponto de vista econômico e ambiental, principalmente quando não necessitam de tratamento térmico para adquirirem caráter pozolânico satisfatório, porque reduzem significativamente a energia de produção do clinquer e a liberação de $\mathrm{CO}_{2}$ proveniente tanto da descarbonatação da calcita como da combustão de combustíveis fósseis. Contudo, dados sobre reservas de zeólitas naturais são escassos e imprecisos. No Brasil, não existe conhecimento sobre depósitos naturais de zeólitas que possam ser explorados comercialmente. No nordeste do Brasil existe a ocorrência de zeolitas sedimentares relacionadas a arenitos descoberta nos anos 2000. Estes arenitos são constituídos de quartzo, argilominerais e zeolitas naturais (estilbita). O objetivo geral desse trabalho foi avaliar se esta zeólita natural presente no arenito possui atividade pozolânica satisfatória para ser empregada como adição mineral em cimentos Portland. No programa experimental o arenito zeolítico passou por beneficiamento através da remoção, por peneiramento, do quartzo e outros minerais inertes, de modo a concentrar a zeólita estilbita e com isto verificar as propriedades pozolânicas deste mineral. No estudo experimental foram empregadas as técnicas de difração de raios X, calorimetria, ensaios químicos e de determinação da atividade pozolânica em argamassas de cal hidratada e cimento Portland. Os resultados mostraram que o arenito zeolítico acelerou a hidratação do cimento Portland devido a extrema finura do material. O arenito apresentou atividade pozolânica, sendo a estilbita responsável por este comportamento. Entretanto, a reatividade foi ligeiramente inferior ao mínimo exigido para ser empregado em escala industrial como pozolana. Estudos complementares são necessários para averiguar se o tratamento térmico entre $300{ }^{\circ} \mathrm{C}$ e $500{ }^{\circ} \mathrm{C}$ pode aumentar a atividade pozolânica do arenito devido a destruição da estrutura cristalina tanto da estilbita quanto da esmectita presente no arenito. Palavras-chave: cimento Portland, materiais pozolânicos, zeólitas, estilbita.
\end{abstract}

\begin{abstract}
Natural zeolites usually exhibit pozzolanic activity without any additional treatment, e.g. thermal activation. They have been used for building since the ancient Roman Empire times in the production of hydraulic cements and concretes. Nowadays, there are many discussions involving the natural zeolites pozzolanic reactivity in the incorporation of the Portland cement composition. The appropriate use of pozzolans enables the production of special cements with lower manufacturing cost and with a greater durability in comparison with the corresponding cements without addition. In Brazil, zeolite consumption comes either from the importation of foreign countries or synthetic products. No zeolite mine is available in the country and only few geological occurrences were already described in the literature without any commercial interest. In northeast Brazil, the Geological Survey (CPRM) discovered zeolite-bearing sandstones related to Cretaceous sedimentary rocks of the Parnaiba Paleozoic Basin. The main purpose of this paper is to evaluate the possible use of such sandstones as pozzolan for using in Portland cements (CPI-S). A bulk sample of the zeolitic sandstone (AZ) was collected in the field. In the laboratory, preparation included drying, milling and sieving at the following grain-size fractions, in order to remove quartz. and concentrate the zeolite: 100\# (AZ-1), 200\# (AZ-2) and 325\# (AZ-3). After mineralogical evaluation, the AZ-2 fraction was selected for further analysis and assays. The experimental study was mainly based on mineralogical characterization, including: X-ray diffraction (XRD), chemical analysis and heat flow calorimetry, besides pozzolanic activity assay and compressive strength. The results show that the mineralogical composition of the zeolitic sandstone is mainly quartz, zeolite (stilbite) and smectite. Stilbite is the main pozzolanic phase, and the smectite can also play an important role. The hydration of the Portland cement was accelerated due to the very fine grained nature of the material. Meanwhile, the reactivity obtained was slightly below the standard requirements to be used in industrial scale. Additional studies should be carried out in order to evaluate if a further thermal treatment (between $300{ }^{\circ} \mathrm{C}$ and $500{ }^{\circ} \mathrm{C}$ ) may increase the pozzolanic activity due to the stilbite destruction around this temperature. The same happens with kaolinite that needs thermal treatment above 550 ${ }^{\circ} \mathrm{C}$ to convert to the amorphous phase metakaolin in order to be used as one of the most commons pozzolans in the cement industry. The main purpose was to contribute for the production of an alternative kind of cement which produces less pollution to the environment $\left(\mathrm{CO}_{2}\right.$ decrease in the atmosphere) with cost saving. In addition, it is expected to contribute for the exploitation of the sedimentary zeolites occurrences which have been relatively well studied from a geological point, but are still not mined.
\end{abstract}

Keywords: Portland cement, pozzolan, zeolites, stilbite. 


\section{INTRODUÇÃO}

As zeólitas naturais são formadas pela alteração de vidros vulcânicos ou a partir da precipitação de fluidos contidos nos poros nas ocorrências hidrotermais. Dependendo das condições de temperatura, pressão, atividade das espécies iônicas e a pressão parcial da água, serão formados diferentes tipos de zeólitas. A maioria das zeólitas encontradas está relacionada aos ambientes geológicos salinos ou lagos salinos, solos alcalinos, diagenético, sistema aberto, hidrotermal e sedimentos marinhos [1]. O uso das zeólitas data desde a época do império romano, quando empregavam misturas de cinzas vulcânicas ou tufos alterados, cal e água para fabricação dos primeiros cimentos hidráulicos, resistentes à ação da água. Posteriormente, tufos vulcânicos zeolíticos passaram a ser empregado na construção de muitas catedrais e prédios públicos na Europa devido à baixa densidade aparente que facilitava o corte em blocos. Contudo, somente na década de 40 , com o aumento do interesse comercial pelos depósitos sedimentares de zeólitas devido ao baixo custo de lavra, é que estes minerais foram identificados na composição das cinzas e tufos vulcânicos [2]. As misturas de cinzas ou tufos, cal e água, foram os primeiros cimentos com compostos hidráulicos resistentes a ação da água. Foram os precursores do cimento Portland, aglomerante hidráulico produzido pela sinterização e moagem do clínquer. Este é constituído de nódulos de 5 a $25 \mathrm{~mm}$ de diâmetro de material sinterizado, formado a partir da calcinação a altas temperaturas de misturas prédeterminadas de matérias primas de cálcio e sílica, que originam os silicatos de cálcio hidráulicos, acrescido de uma ou mais formas de sulfatos de cálcio como um produto de controle da pega [3].

Uma vasta gama de cimentos Portland é produzida atualmente a partir do tipo e da quantidade de adições minerais incorporadas ao cimento. A busca por cimentos de baixo consumo energético e de baixa emissão de $\mathrm{CO}_{2}$ faz das adições minerais um dos temas de maior interesse nas pesquisas sobre química e mineralogia do cimento. A pozolana é uma destas adições minerais, definida como um material silicoso ou aluminossílicoso, que por si só não possui propriedade cimentante. Porém, quando finamente dividida e na presença de umidade, reage quimicamente com a cal hidratada ou hidróxido de cálcio $\left(\mathrm{Ca}(\mathrm{OH})_{2}\right)$ a temperatura ambiente para formar compostos com propriedades cimentantes. O hidróxido de cálcio é instável em água; no entanto, pode carbonatar-se lentamente ao ar para formar um produto estável, a calcita $\left(\mathrm{CaCO}_{3}\right)$. Quando a pozolana (sílica reativa) está presente no sistema são formados os silicatos de cálcio hidratados, que são estáveis à ação da água a partir da reação entre o hidróxido de cálcio e a pozolana [3]. A atividade pozolânica das zeólitas se deve à sua estrutura cristalina microporosa, com canais e cavidades interconectadas de dimensões moleculares, que faz com que possuam uma área superficial específica muito elevada. Estas características proporcionam às zeólitas reatividade considerável com a cal hidratada e por isto são muito importantes do ponto de vista econômico e ambiental, principalmente quando não necessitam de tratamento térmico para adquirirem um caráter pozolânico satisfatório, o que faz com que haja uma redução significativa na energia de produção do clinquer e na liberação de $\mathrm{CO}_{2}$ proveniente tanto da descarbonatação da calcita como da combustão de combustíveis fósseis [3]. Cerca de 95\% das zeólitas naturais podem ser utilizadas como material ativo na produção de cimento Portland pozolânico, com destaque para a clinoptilolita, phillipsita, herschelita e a analcima entre outras. O percentual de incorporação no cimento geralmente encontra-se entre $5 \%$ e $20 \%$ [2].

Os dados sobre as reservas mundiais de zeólitas são pouco conhecidos, mas Cuba apresenta-se como o maior detentor, com 669 milhões de toneladas dos depósitos conhecidos [2, 4]. No Brasil não foram ainda encontrados depósitos naturais para a exploração comercial. Existem apenas estudos sobre ocorrências que não apresentam potencialidade de aproveitamento, como os basaltos e diabásios da bacia do Paraná e as drusas e cavidades da zona de contato dos tactitos e micaxistos na mina Barra Verde em Currais Novos, RN [5]. Em meados dos anos 1990, em trabalhos realizados pela CPRM (Companhia de Pesquisa de Recursos Minerais), foi descoberto no nordeste brasileiro, mais especificamente na Bacia do Parnaíba, zeólitas sedimentares que estão relacionadas a arenitos pertencentes à Formação Corda, de idade eo-mesozóica. De acordo com os primeiros trabalhos geológicos e de caracterização química e mineralógica que foram realizados nestas ocorrências, as zeolitas constituintes deste tipo de arenito são as estilbitas [6].

Este trabalho teve como objetivo avaliar, preliminarmente, a atividade pozolânica do arenito zeolítico beneficiado por peneiramento, caracterizando-o química, física e mineralogicamente, com vistas a sua utilização como adição mineral em cimentos Portland.

\section{Localização e contexto geológico da ocorrência}

A área de ocorrência dos arenitos zeolíticos da Formação Corda ocupa uma vasta área ao longo da BR-010 (BelémBrasília), nos arredores da cidade de Imperatriz, MA, estendendo-se até o estado do Tocantins, estando bastante próximos de várias fábricas de cimento Portland localizadas nos estados do Pará, Maranhão e Tocantins, e por isto, podem se constituir em uma fonte potencial de matéria-prima para fabricação de pozolana. A localização dos depósitos é mostrada na Fig. 1.

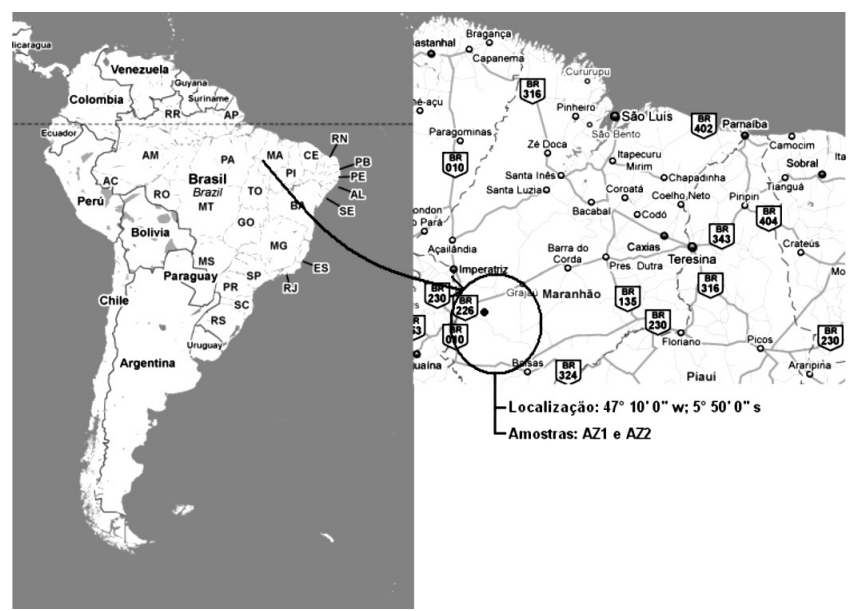

Figura 1: Mapa com a localização dos pontos de coleta do arenito zeolítico. Fonte: CPRM.

[Figure 1: Map showing the location of the collection sites of zeolitic sandstone. Source: CPRM.] 
O contexto geológico local reflete um amplo sistema sedimentar predominantemente eólico e fluvial, desenvolvido sobre derrames basálticos [4-6]. A composição mineralógica foi determinada, principalmente, por difração de raios X, na qual duas fases distintas podem ser destacadas: a) detrítica, contendo grãos de composição diversificada, na qual predomina o quartzo e, subordinadamente, fragmentos de basalto, além de feldspatos, quartzito, chert e calcário, entre outros; b) fase autigênica, com a paragênese envolvendo um coating ferruginoso recobrindo os grãos de quartzo, esmectitas (predominatemente montmorillonitas), zeolitas (estilbita e laumontita) e calcita. É muito importante

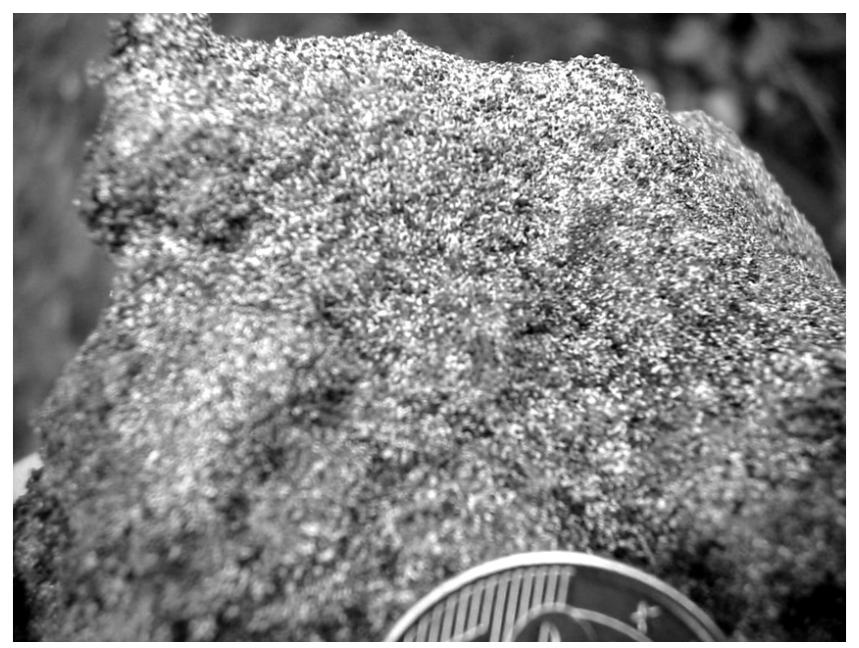

Figura 2: Detalhe de amostra de mão dos arenitos zeolíticos da Formação Corda, $1^{\circ}$ ponto de amostragem (AZ1) utilizado neste trabalho. Os grãos de quartzo apresentam coloração avermelhada, em função de coating de goethita, enquanto as porções esbranquiçadas são o cimento zeolítico.

[Figure 2: Detail of hand sample of the sandstone formation of zeolitic Rope, $1^{\text {st }}$ sampling point (AZ1) used in this work. The quartz grains exhibit reddish, depending on the coating of goethite, while the white portions are the zeolitic cement.]

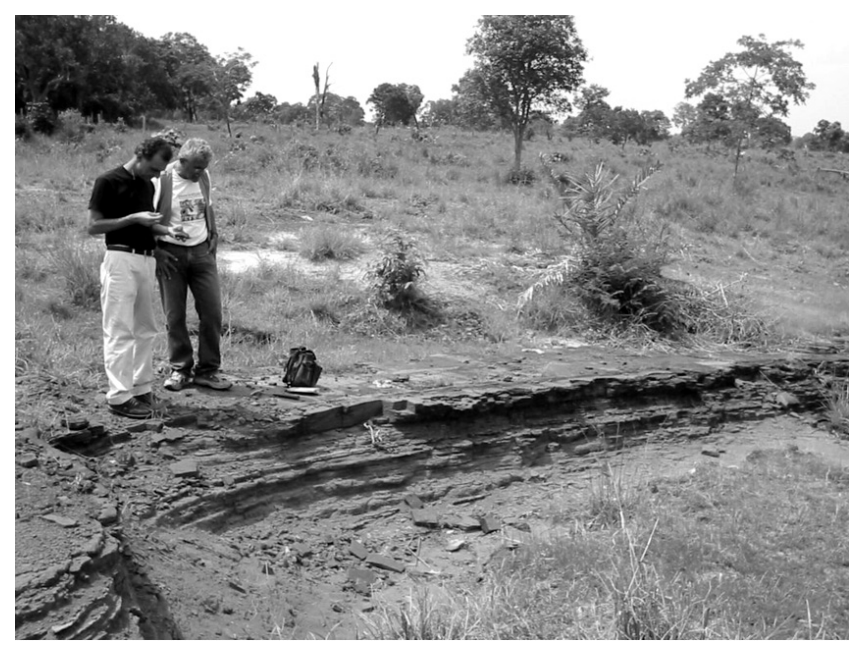

Figura 3: Vista geral do afloramento dos arenitos zeolíticos da Formação Corda, $1^{\circ}$ ponto de amostragem (AZ1) utilizado neste trabalho.

[Figure 3: Overview of the outcrop of sandstones zeolitic Training Rope, $1^{\text {st }}$ sampling point (AZ1) used in this work.] destacar que, geologicamente, este é um caso raro de uma rocha sedimentar, um arenito, com proporções relativamente tão elevadas de cimento zeolítico A textura do arenito é caracterizada por um empacotamento predominantemente flutuante e/ou pontual. A Fig. 2 ilustra uma amostra de mão do arenito zeolítico, enquanto a Fig. 3 um aspecto típico de campo dos afloramentos desse arenito. Em outros pontos de afloramento também foram identificadas, em menores quantidades, outras zeólitas do tipo laumontita e clinoptilolita [5].

\section{MATERIAIS E MÉTODOS}

Foram analisadas amostras de arenito zeolítico da Bacia do Paraíba, pertencente à Formação Corda, coletadas nas proximidades da cidade de Imperatriz. A preparação das amostras de arenito consistiu de um processo de peneiramento a seco, com o aproveitamento do material passante, tendo em vista que nestas frações de granulometria mais fina estão concentradas as fases pozolânicamente ativas como as zeólitas e os argilominerais. O tratamento inicial da amostra de arenito zeolítico coletada no campo (cerca de $20 \mathrm{~kg}$ ) consistiu de secagem ao ar livre, desagregação e posterior moagem em moinho de bolas por $2 \mathrm{~h}$. Depois a amostra foi passada nas peneiras 100\# (AZ1), 200\# (AZ2) e 350\# (AZ3). O material passante teve sua constituição mineralógica determinada por difração de raios X (DRX). Este estudo subsidiou a escolha da melhor fração (mais enriquecida em zeólita) que seria utilizada para os ensaios de caracterização química e mineralógica, calorimetria de condução e determinação da atividade pozolânica com cimento Portland e cal. Os critérios de determinação adotados neste estudo preliminar foram o percentual de material passante em relação à amostra total, os minerais constituintes e suas concentrações na amostra.

As análises químicas foram feitas por espectrometria de fluorescência de raios X (FRX) em pastilhas fundidas (elementos maiores), em que cerca de $1 \mathrm{~g}$ de amostra pulverizada é misturado a $8 \mathrm{~g}$ de fundente tetraborato de lítio $\left(\mathrm{Li}_{2} \mathrm{~B}_{4} \mathrm{O}_{7}\right)$. Essa mistura é previamente submetida à homogeneização para melhor agregar a amostra. Em seguida essa mistura foi fundida a $\sim 1200{ }^{\circ} \mathrm{C}$ em um cadinho de platina. Os elementos traços foram analisados em pastilha prensada. Os dados foram adquiridos através do software SuperQ Manager, e o tratamento dos dados foi feito no software $I Q+$, ambos da PANalytical.

A composição mineralógica foi determinada por difração de raios X, método do pó. As análises foram realizadas em difratômetro PANalytical X’Pert Pro MPD (PW 3040/60) com goniômetro PW3050/60 ( $\theta / \theta)$, tubo de raios X cerâmico com anodo de Co $(\mathrm{K} \alpha=1,789 \AA$ A), PW3373/00, foco fino longo, filtro $\mathrm{FeK} \beta$, de 5 a $70^{\circ}$ em $2 \theta, 40 \mathrm{kV}, 40 \mathrm{~mA}$, passo $0,02^{\circ}$ em $2 \theta$ e tempo/passo $60 \mathrm{~s}$, fenda divergente $1 / 8^{\circ}$ e de anti-espalhamento $1 / 4^{\circ}$, máscara de $10 \mathrm{~mm}$, amostra em movimentação circular de 1 rotação/s. Além da análise das amostras in natura, foi feita a identificação de fases da amostra calcinada entre $100{ }^{\circ} \mathrm{C} \mathrm{e} 1000{ }^{\circ} \mathrm{C}$, em intervalos de $100{ }^{\circ} \mathrm{C}$ com vistas a observar a ocorrência e/ou formação de novas fases mineralógicas. A identificação das fases é feita com o programa High Score Plus, por comparação do padrão difratométrico com arquivos ICDD-PDF (Internacional Center for Diffraction Data, Powder Diffraction File).

$\mathrm{Na}$ análise da calorimetria de condução foi empregado 
um microcalorímetro isotermal. O fluxo de calor produzido durante as reações de hidratação passa por termopares especiais, constituídos por 71 elementos semicondutores de BiTe, conectados em série. A mudança na temperatura, causada pela evolução do calor durante a hidratação, excita os semicondutores, resultando em uma voltagem, medida em um multímetro digital. Os dados adquiridos em $\mathrm{nV}$ ou $\mu \mathrm{V}$ são gravados instantaneamente por um computador e são convertidos para unidades de fluxo de calor através da calibração do equipamento $(\mathrm{mW} / \mathrm{g})$. Os ruídos são reduzidos significativamente através da ligação de termopares em polos opostos, sendo um termopar para a amostra e outro para uma referência inerte (alumina pulverizada), que possui a mesma capacidade térmica do material da amostra. $\mathrm{O}$ equipamento possui 4 porta-amostras, sendo um para a referência e os demais para as pastas. Como referencia utilizou-se uma mistura de $2 \mathrm{~g}$ de água com $2 \mathrm{~g}$ de óxido de alumínio e cadinhos de aço nas seguintes características: quantidade de amostra em cada cadinho $4 \mathrm{~g}$ ( $2 \mathrm{~g}$ de amostra e $2 \mathrm{~g}$ de água), constante de tempo $50 \mathrm{~s}$, sensibilidade a 25 ${ }^{\circ} \mathrm{C}$ de $98 \mu \mathrm{V} / \mathrm{mW}$, cadinho de aço e resolução de $2 \mu \mathrm{W}$. Três pastas foram analisadas, a primeira constituída apenas com cimento Portland CPI-S e água, na segunda e terceira amostras, 25 e $50 \%$ do cimento Portland foi substituído pelo arenito zeolítico AZ2, respectivamente. A relação água/ aglomerante (cimento + adição mineral) das pastas foi $1 \mathrm{e}$ o cimento empregado, no caso o CPI-S, é isento de adições minerais ativas, sendo constituído por $95 \%$ de clínquer e $5 \%$ de gesso e outras adições inertes.

A atividade pozolânica do arenito foi determinada tanto com a cal hidratada quanto com o cimento Portland (CPI-S). O ensaio que mediu a atividade pozolânica por meio de resultados mecânicos de argamassas com cal hidratada obedeceu às prescrições da NBR 5751 [7]. O proporcionamento da argamassa, constituída de cal hidratada, pozolana (no caso o arenito AZ2), areia normal e água, é feito de forma que o volume de pozolana seja duas vezes o volume do hidróxido de cálcio (cal hidratada). A quantidade de água a ser adicionada é aquela necessária à obtenção de uma consistência de $225 \pm 5 \mathrm{~mm}$, medida na mesa de consistência. As pozolanas consideradas satisfatórias são aquelas que exibem aos 7 dias valores de resistência à compressão iguais ou superiores a 6,0 MPa. Foi empregado na elaboração da argamassa hidróxido de cálcio PA.

Para o ensaio mecânico em argamassas com cimento Portland (CPI-S) seguiram-se as diretrizes da NBR 5752 [8], na qual a determinação da atividade pozolânica de um material é função do comportamento mecânico de duas argamassas, preparadas com traço em massa de $1: 3$ e consistência padronizada de $225 \pm 5 \mathrm{~mm}$ (mesa de consistência). A primeira argamassa, admitida como de referência, tem apenas cimento, areia normal e água, enquanto que na segunda argamassa, parte do volume de cimento (35\%) é substituído pela pozolana que se pretende analisar. O índice de atividade pozolânica com cimento Portland (IAP) é definido como a relação entre as resistências à compressão aos 28 dias da argamassa com pozolana e cimento Portland e a de referencia (somente com cimento Portland). Para que um material seja considerado pozolânico, este índice, normalmente expresso em porcentagem, deve ser superior a $75 \%$. Foram moldadas duas argamassas, sendo uma de referência e a outra com o arenito AZ2. O cimento utilizado foi o mesmo da análise granulométrica.

\section{RESULTADOS E DISCUSSÃO}

\section{Caracterização mineralógica}

Os difratogramas de raios $X$ com os minerais identificados nas amostras AZ-1, AZ-2 e AZ-3 estão apresentados na Fig. 4. A composição mineralógica é representada por quartzo, zeólita estilbita e esmectita. No caso da estilbita, a melhor ficha desse mineral no ICDD-PDF é a 44-1479. Outras zeólitas podem estar presentes, em pequenas quantidades, como laumontita e heulandita, sugeridas a partir da presença apenas do pico principal de cada uma. Na figura é nítido o aumento da intensidade do pico principal da estilbita (e diminuição do quartzo), ou seja, o aumento relativo da sua concentração, da amostra AZ-1 (100\#, mais rica em quartzo), em direção a amostra AZ-3 (325\#). A decisão sobre a fração granulométrica a ser utilizada para os ensaios seguintes recaiu sobre a amostra AZ2 (200\#), em função do volume de material passante $(15 \%$, em relação a massa total). A amostra AZ-3 (325\#), apesar de mostrar a maior concentração de zeólita, apresentou apenas $2 \%$ de material passante, o que poderia inviabilizar futuro aproveitamento em larga escala. O volume passante na amostra AZ-1 (100\#) foi de mais de $70 \%$, porém com baixa concentração de zeólita. Adicionalmente, podem estar presentes, em pequena quantidade, K-feldspatos e goethita, representados pelos seus picos principais, de pequena intensidade. Em relação a esmectita, a mesma é identificada, nos difratogramas, pelo pico principal ou banda larga, no início do difratograma, representando o espaçamento interlamelar $\left(\mathrm{d}_{001}\right)$, em torno de $15 \AA$ ( $7^{\circ} 2 \theta$, na Fig. 4). Trabalhos anteriores [4] já descreveram a presença de esmectita associada aos arenitos zeolíticos da Formação Corda e mostraram que se trata de uma montmorilonita, após separação da fração argila, e análise por DRX das lâminas orientadas (seca ao ar, glicolada e aquecida a $550{ }^{\circ} \mathrm{C}$ ), além da análise do pico (060). Maiores considerações em relação a este argilomineral serão feitas posteriormente, já que o mesmo também pode apresentar propriedades pozolânicas.

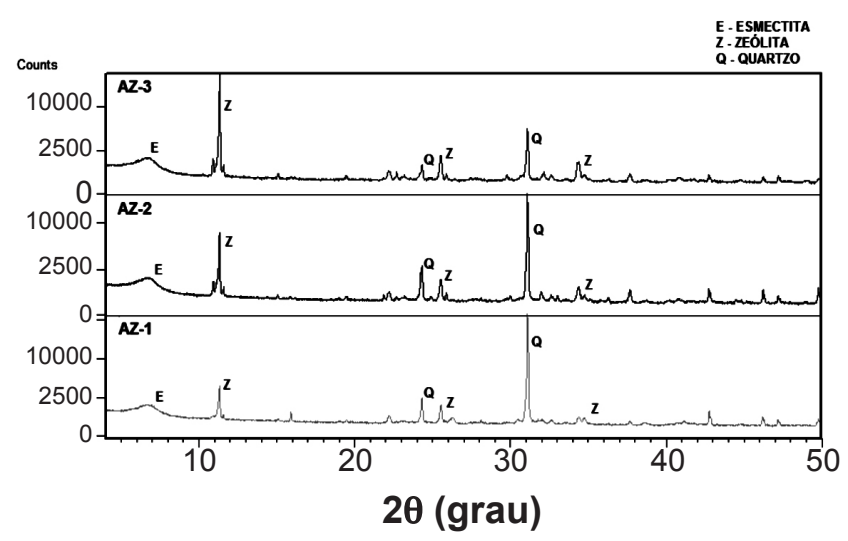

Figura 4: Difratogramas de raios X das amostras AZ-1, AZ-2 e AZ-3. [Figure 4: X-ray diffraction patterns of samples AZ-1, AZ-2 and AZ-3.]

\section{Análise química}

Com base na seleção da melhor fração a ser trabalhada, conforme descrito anteriormente, as análises químicas 
Tabela I - Resultados da análise química da amostra AZ-2. [Table I - Results of chemical analysis of the sample AZ-2.]

\begin{tabular}{cc}
\hline $\begin{array}{c}\text { Elementos Maiores } \\
(\%)\end{array}$ & $\mathrm{AZ}-2$ \\
\hline $\mathrm{SiO}_{2}$ & 76,16 \\
$\mathrm{Al}_{2} \mathrm{O}_{3}$ & 7,68 \\
$\mathrm{Fe}_{2} \mathrm{O}_{3}$ & 2,73 \\
$\mathrm{TiO}_{2}$ & 0,37 \\
$\mathrm{CaO}$ & 2,07 \\
$\mathrm{MgO}$ & 1,01 \\
$\mathrm{Na} \mathrm{O}_{2}$ & 0,19 \\
$\mathrm{~K}_{2} \mathrm{O}$ & 1,48 \\
$\mathrm{Cr}_{2} \mathrm{O}_{3}$ & 0,02 \\
$\mathrm{MnO}_{2}$ & 0,06 \\
$\mathrm{P}_{2} \mathrm{O}_{5}$ & 0,06 \\
$\mathrm{TiO}_{2}$ & 0,37 \\
$\mathrm{P.F.}$ & 8,00 \\
Total & $\mathbf{9 9 , 8 2}$ \\
\hline
\end{tabular}

P.F. : Perda ao fogo determinada com a queima a $1000{ }^{\circ} \mathrm{C}$.

Tabela II - Resultados da análise química da amostra AZ-2 (Elementos traços).

[Table II - Results of chemical analysis of the sample AZ-2 (trace elements).]

\begin{tabular}{cc}
\hline $\begin{array}{c}\text { Elementos-Traço } \\
(\mathrm{ppm})\end{array}$ & $\mathrm{AZ}-2$ \\
\hline $\mathrm{Ni}$ & 24 \\
$\mathrm{Sc}$ & 7 \\
$\mathrm{Ba}$ & 1089 \\
$\mathrm{Be}$ & $<1$ \\
$\mathrm{Co}$ & 25 \\
$\mathrm{Cs}$ & $<1$ \\
$\mathrm{Ga}$ & 5 \\
$\mathrm{Hf}$ & 2 \\
$\mathrm{Nb}$ & 4 \\
$\mathrm{Rb}$ & 33 \\
\hline
\end{tabular}

foram realizadas apenas na amostra AZ2, cujos resultados obtidos estão apresentados na Tabela I (elementos maiores) e na Tabela II (elementos traços). A mesma apresentou teor bastante elevado de $\mathrm{SiO}_{2}(76,16 \%)$, relacionado à estrutura dos principais minerais descritos (quartzo, estilbita e esmectita), além de $\mathrm{Al}_{2} \mathrm{O}_{3}(7,68 \%)$, relacionado a estilbita e a esmectita e $\mathrm{Fe}_{2} \mathrm{O}_{3}{ }^{2}(2,73 \%)$, relacionado a goethita. A soma dos percentuais desses três óxidos é igual a $86,57 \%$, valor este maior que $70 \%$ proposto pela norma da ABNT [9]. Isto significa que o material estudado provavelmente tem potencial para possuir atividade pozolânica. Outros elementos analisados, como $\mathrm{CaO}(2,07 \%)$ e $\mathrm{K}_{2} \mathrm{O}(1,48 \%)$, estão relacionados a estrutura da estilbita e K-feldspato, respectivamente. O valor de perda ao fogo obtido é de 8,00\% e está relacionado, principalmente, à água e/ou hidroxilas nas estruturas da estilbita e da esmectita.

\section{Estudo da estabilidade térmica}

Foi realizado um estudo da estabilidade térmica do material estudado, em função do aumento da temperatura, acompanhado da avaliação das transformações de fase com a DRX. Os difratogramas obtidos dos produtos calcinados, de $100{ }^{\circ} \mathrm{C}$ a $1000{ }^{\circ} \mathrm{C}$ estão apresentados nas Figs. 5 e 6, com as principais fases identificadas. Quartzo está presente em todas as amostras, pois não apresenta modificação de sua estrutura cristalina nesta faixa de temperatura. $\mathrm{O}$ mesmo acontece com o K-feldspato, que apresenta grandes variações na intensidade do pico principal. Acredita-se que pode ser efeito de orientação preferencial (preenchimento do pó no porta-amostra), já que esses picos correspondem aos planos principais de clivagem desse mineral. Porém, o principal efeito do tratamento térmico é o desaparecimento do pico principal da esmectita, a partir de $200{ }^{\circ} \mathrm{C}$ e a diminuição progressiva do pico principal da estilbita, com o seu total desaparecimento a partir de $400{ }^{\circ} \mathrm{C}$. O desaparecimento dos picos revela a destruição da estrutura dos minerais,

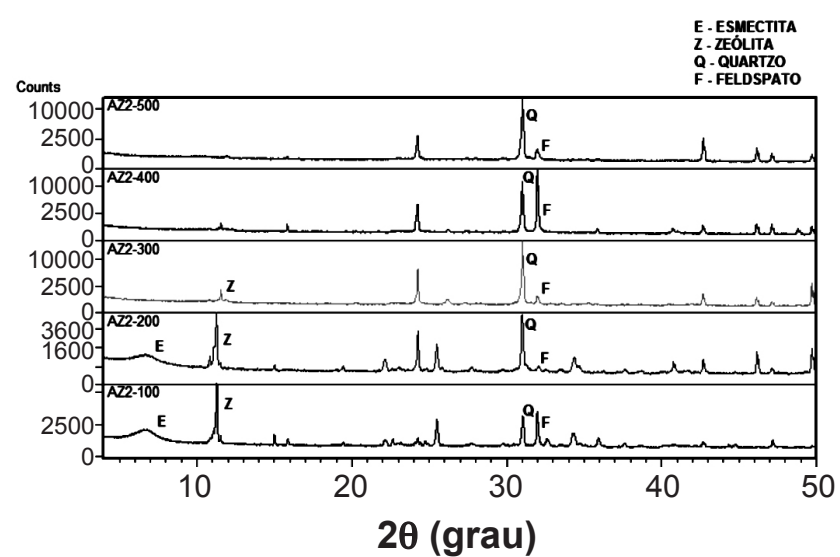

Figura 5: Difratogramas de raios $\mathrm{X}$ dos resultados do ensaio de calcinação das amostras AZ2 de 100 a $500{ }^{\circ} \mathrm{C}$.

[Figure 5: X-ray diffraction patterns of samples calcined AZ2 100$500^{\circ} \mathrm{C}$.]

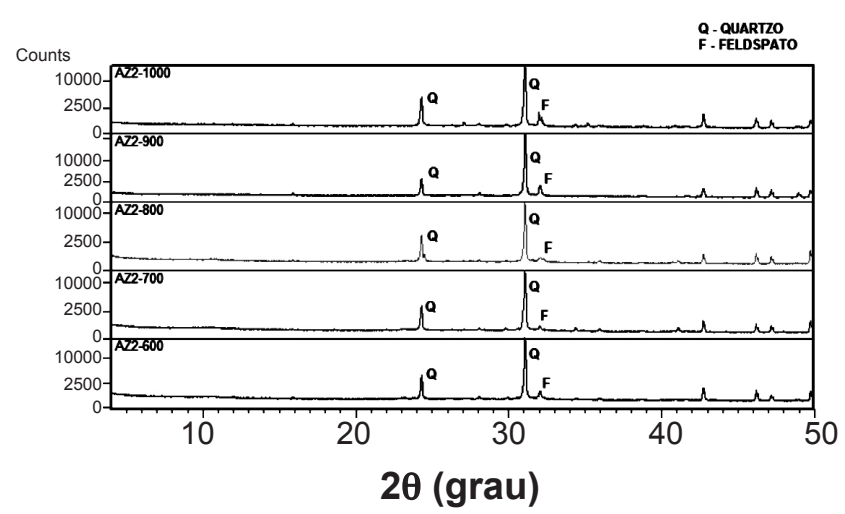

Figura. 6: Difratogramas de raios $\mathrm{X}$ dos resultados do ensaio de calcinação das amostras AZ2 de 600 a $1000{ }^{\circ} \mathrm{C}$.

[Figure 6: X-ray diffraction patterns of samples calcined AZ2 600$\left.1000^{\circ} \mathrm{C}.\right]$ 
principalmente da estilbita, nas temperaturas indicadas, a partir das quais, essas fases passariam a demonstrar suas atividades pozolânicas. Vale destacar que, a caulinita, um abundante argilomineral da natureza é convertido em metacaulinita (amorfo) a partir de $550{ }^{\circ} \mathrm{C}$, quando passa a ter atividade pozolânica e ampla aplicação na indústria do cimento, para aumentar a resistência de concretos [3, 10]. Em relação à esmectita, a destruição ou colapso do pico principal, de fato, não implica na completa desordem estrutural da mesma, a partir de $200{ }^{\circ} \mathrm{C}$. A princípio, ocorre a perda da água interlamelar e a estrutura resultante se assemelha a da mica $\left(\mathrm{d}_{001}=10 \AA\right)$. A destruição completa se daria acima de $550{ }^{\circ} \mathrm{C}$, semelhante a da caulinita.

\section{Avaliação da reatividade do arenito}

A Fig. 7 mostra a evolução do fluxo de calor da pasta de referência somente com cimento Portland CPI S e com $25 \%$ e $50 \%$ de substituição do cimento Portland pelo AZ2, determinada no microcalorímetro de condução. A Tabela III apresenta a quantidade de calor gerada pelas reações de hidratação das pastas com cimento Portland, com e sem o AZ2.

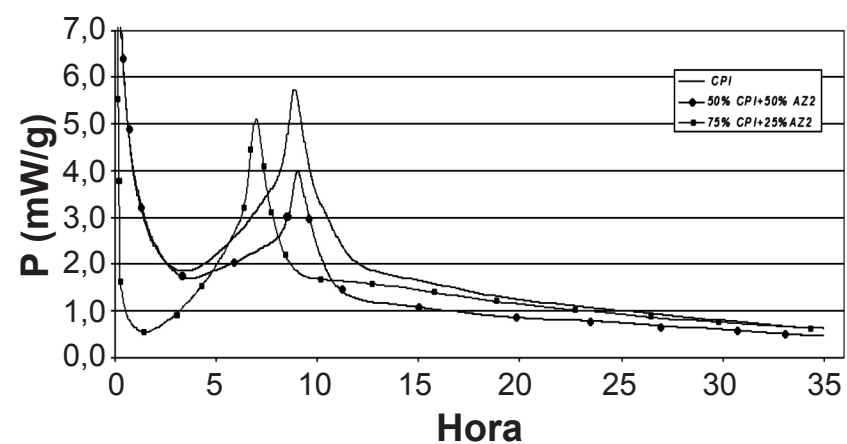

Figura 7: Calorimetria de cimento Portland e zeólita.

[Figure 7: Calorimetry of Portland cement and zeolite.]

A incorporação de $25 \%$ do arenito zeolítico (AZ-2) modificou a configuração da curva de evolução de calor, antecipando a reações de hidratação em pelo menos $3 \mathrm{~h}$, além de gerar um calor total superior ao da pasta de referência. Enquanto a pasta de referencia, com cimento Portland, gerou um calor total de $52,00 \mathrm{~mW} . \mathrm{h} / \mathrm{g}$, a pasta com $25 \%$ de AZ2 gerou $59 \mathrm{~mW} . \mathrm{h} / \mathrm{g}$ ao final de $60 \mathrm{~h}$ de hidratação (Tabela III). A aceleração na hidratação dos compostos do cimento, $\mathrm{C}_{3} \mathrm{~S}$ e $\mathrm{C}_{3} \mathrm{~A}$, foi ocasionada pela finura das partículas do arenito como também pela presença do $\mathrm{Al}$ de coordenação tetraédrica no AZ-2. Neste último caso, o Al de coordenação tetraédrica na zeólita atua na estrutura do C-S-H não como monômeros ou grupos terminais, mas sim como ponte de ligação para originar dímeros, pentâmeros e octameros [11]. A aceleração da hidratação do cimento Portland também ocorre porque as partículas extremamente finas desse material atuam como pontos de nucleação para cristalização dos produtos de hidratação [12].

Com relação à amostra com $50 \%$ de substituição, o efeito de diluição do cimento foi preponderante sobre a aceleração da hidratação do cimento induzida pelo arenito, o que repercute em uma área da curva de evolução de calor inferior a da gerada pela pasta de referência, sem
Tabela III - Análise das reações de hidratação do cimento Portland com zeólita.

[Table III - Analysis of the hydration reactions of Portland cement with zeolite.]

\begin{tabular}{|c|c|c|c|}
\hline \multirow[b]{2}{*}{ Amostra } & \multicolumn{2}{|c|}{ Quantidade (\%) } & \multirow{2}{*}{$\begin{array}{l}\text { Energia de } \\
\text { hidratação } \\
(\mathrm{mW} \cdot \mathrm{h} / \mathrm{g})\end{array}$} \\
\hline & Cimento & $\begin{array}{c}\text { Arenito } \\
\text { Zeolítico }\end{array}$ & \\
\hline $\mathrm{CPI}-\mathrm{S}$ & 100 & 0 & 58,87 \\
\hline $50 \% \mathrm{CPI}+\mathrm{AZ}-2-50$ & 50 & 50 & 39,96 \\
\hline $75 \% \mathrm{CPI}+\mathrm{AZ}-2-25$ & 75 & 25 & 52,03 \\
\hline
\end{tabular}

antecipação das reações de hidratação (Fig. 7). O calor total gerado pela pasta com $50 \%$ de arenito foi substancialmente menor que o da pasta de referencia, cerca de $40 \mathrm{~mW} . \mathrm{h} / \mathrm{g}$ em comparação ao $52,00 \mathrm{~mW} . \mathrm{h} / \mathrm{g}$ da pasta de referencia . A calorimetria demonstrou que a incorporação de $25 \%$ do arenito zeolítico AZ2 ao cimento Portland apresentaram reatividade satisfatória, corroborando com os relatos da literatura e da prática industrial, que incorporam percentuais de substituição de cimento Portland por zeólitas de até $20 \%$.

\section{Avaliação da atividade pozolânica}

Na Tabela IV são mostrados os resultados da atividade pozolânica do arenito zeolítico com a cal hidratada. É estabelecido o limite mínimo de 6,0 $\mathrm{MPa}$ para argamassas de pozolana, cal e areia normal para que um material seja considerado pozolânico [7]. $\mathrm{O}$ arenito $\mathrm{AZ}-2$ não atendeu a esta exigência, uma vez que a média da resistência a compressão dos corpos-de-prova foi de 5,0 MPa, cerca de $83 \%$ do limite mínimo estipulado pela norma. De modo análogo ao observado no ensaio com a cal hidratada, a argamassa de cimento Portland com a incorporação do AZ-2 não atendeu ao limite mínimo estabelecido de $75 \%$ da resistência da argamassa de referência (Tabela V). O IAP da argamassa com AZ-2 foi de aproximadamente $55 \%$, bastante inferior ao limite de $75 \%$ estabelecido pela norma. Neste caso, a baixa reatividade se deve a metodologia do ensaio prescrito na norma, que contribui para este tipo de distorção nos resultados, pois prevê percentuais de incorporação superiores a $30 \%$, valor muito superior ao recomendado para o emprego de zeolitas em cimento, que é de 5 a 20\%. Os resultados da atividade pozolânica com cal hidratada e cimento Portland, portanto, não significam que o material seja inerte e sua aplicação inviável, apenas que sua reatividade não foi suficiente para atender aos limites mínimos estabelecidos pelas condiçõos de ensaio da norma. A reatividade pode ser incrementada com tratamento térmico a baixas temperaturas. Acredita-se que se este material for

Tabela IV - Índice de atividade pozolânica com a cal da amostra AZ-2.

[Table IV - Pozolanic activity index with lime sample AZ-2.]

Resistência a

\begin{tabular}{ccccc} 
Argamassa & \multicolumn{3}{c}{ Compressão simples } & Média \\
& 1 & 2 & 3 & \\
\hline Mistura AZ-2 com Cal & 4,94 & 5,12 & 4,96 & 5,01 \\
\hline
\end{tabular}


Tabela V - Índice de atividade pozolânica com cimento da amostra AZ-2.

[Table V - Pozolanic activity index with cement sample AZ-2.]

\begin{tabular}{cccccc}
\hline \multicolumn{5}{c}{ Resistência a } \\
Argamassa & \multicolumn{3}{c}{$\begin{array}{c}\text { Compressão simples } \\
\text { (MPa) }\end{array}$} & Média & $\begin{array}{c}\text { I.A.P. CP } \\
\text { (\%) }\end{array}$ \\
\hline $\begin{array}{c}\text { Argamassa de } \\
\text { Referência }\end{array}$ & 33,68 & 36,43 & 37,61 & 35,91 & - \\
$\begin{array}{c}\text { Mistura AZ-2 } \\
\text { com Cimento }\end{array}$ & 19,57 & 19,67 & 19,72 & 19,65 & 54,72 \\
\hline
\end{tabular}

calcinado a temperaturas entre $300 \mathrm{e} 400^{\circ} \mathrm{C}$ pode facilmente alcançar a reatividade prescrita na norma tendo em vista que as estruturas cristalinas, tanto da zeolita quanto da esmectita serão destruídas, potencializando a reatividade do arenito.

\section{CONCLUSÕES}

O arenito zeolítico somente pode ser utilizado após ser submetido ao processo de peneiramento, de modo a reduzir o quartzo e aumentar a concentração das fases pozolânicamente ativas, que no caso são as zeolita estilbita e a esmectita. Os percentuais de aproveitamento do arenito após peneiramento são relativamente reduzidos, entre 5 e $15 \%$ da amostra total, o que pode inviabilizar o seu aproveitamento como material pozolânico para a indústria do cimento. Contudo, isto depende de estudos econômicos aprofundados que não constituem o escopo deste trabalho. $\mathrm{O}$ arenito quando empregado em teores intermediários de substituição do cimento Portland, no caso $25 \%$, acelera a hidratação do cimento Portland e aumenta a quantidade de calor gerado, ao passo que percentuais elevados como $50 \%$ reduzem o calor total gerado e o efeito da aceleração da hidratação é suplantado pelo efeito de diluição do cimento. Estes resultados dão indícios que os teores recomendáveis de incorporação das zeolítas não devem exceder a $25 \%$, apresentando boa concordância com a literatura técnica. A atividade pozolânica do arenito zeolitico "in natura" não alcançou os limites mínimos exigidos pelas normas, mas a reatividade pode ser incrementada quando calcinado a baixas temperaturas, entre 300 e $400{ }^{\circ} \mathrm{C}$, pois as fases pozolanicamente ativas, presentes no arenito, no caso a estilbita e a esmectita, terão suas estruturas cristalinas destruídas. Estudos complementares e aprofundados sobre o comportamento pozolânico deste arenito zeolítico, quando submetido a tratamento térmico a baixas temperaturas, são necessários para obtenção de resultados conclusivos a respeito da sua viabilidade técnica e econômica.

\section{REFERÊNCIAS}

[1] D. L. Bish, D. W. Ming, Natural Zeolites: Occurrence, Properties, Applications, Rev. Mineralogy, Mineral. Soc. Am. 45 (2001) 662.

[2] Th. Perraki, G. Kakali, F. Kontoleon, The effect of natural zeolites on the early hydration of Portland cement, Microporous Mesoporous Mater. 61, 1-3 (2003) 205-212.

[3] K. Mehta, J. P. Monteiro, Concreto: Estrutura, Propriedade e Materiais, Ed. Pini, S. Paulo, SP (1994).

[4] N. G. A. M. Rezende, A zona zeolítica da Formação Corda na Bacia do Parnaíba, Diss. Mestrado, Universidade Federal do Pará, Belém, PA (2002) 142p.

[5] N. G. A. M. Rezende, R. S. Angélica, Sedimentary Zeolites in Brasil, Mineral. Petrogr. Acta 42 (1999) 71-82.

[6] N. G. A. M. Rezende, Argilas Nobres e Zeólitas na Bacia do Parnaíba, Informe de Recursos Minerais, Série Diversos, n. 2. CPRM, Serviço Geológico do Brasil (1997) 50 p.

[7] Associação Brasileira de Normas Técnicas - ABNT 1977 - NBR 5751, Materiais pozolânicos - Determinação de atividade pozolânica com cal.

[8] Associação Brasileira de Normas Técnicas - ABNT 1992 - NBR 5752, Pozolanas - Determinação do índice de atividade pozolânica com cimento Portland.

[9] Associação Brasileira de Normas Técnicas - ABNT NBR 5739, Concreto - Ensaio de compressão de corposde-prova cilíndricos de concreto: Método de ensaio, Rio de Janeiro, RJ (1992).

[10] M. S. Barata, Aproveitamento dos resíduos cauliníticos das indústrias de beneficiamento de caulim da região amazônica como matéria prima para fabricação de um material de construção (pozolanas), Tese Dr., Geologia e Geoquímica, Universidade Federal do Pará, Belém, PA (2007) 396p.

[11] I. G. Richardson, The nature of $\mathrm{C}-\mathrm{S}-\mathrm{H}$ in hardened cements, Cement Concr. Res. 29 (1999) 1131-1147.

[12] S. Wild, J. M. Khatib, A. Jones, Relative strength, pozzolanic activity and cement hydration in superplasticised metakaolin concrete, Cement Concr. Res. 26, 10 (1996) 1537-1544.

(Rec.03/09/2010, Rev. 15/01/2011, Ac. 12/02/2011) 